\title{
Job Satisfaction among Nurses in Public Hospitals in Calabar, Cross River State Nigeria
}

\author{
Samson-Akpan Patience Edoho*, Edet Olaide Bamidele, Ojong Idang Neji, Asuquo Ekaette Frank \\ Department of Nursing Science, University of Calabar, Nigeria
}

Email address:

patedoho2005@yahoo.com (Samson-Akpan P. Edoho), bamideleedet@yahoo.com (E. O. Bamidele), idangojong@yahoo.com (O. I. Neji), frankemile@yahoo.com (A. E. Frank)

\section{To cite this article:}

Samson-Akpan Patience Edoho, Edet Olaide Bamidele, Ojong Idang Neji, Asuquo Ekaette Frank. Job Satisfaction among Nurses in Public Hospitals in Calabar, Cross River State Nigeria. American Journal of Nursing Science. Vol. 4, No. 4, 2015, pp. 231-237.

doi: 10.11648/j.ajns.20150404.22

\begin{abstract}
Background: Job satisfaction is an essential part of nurses' lives, influencing patient safety, productivity, performance, quality of care, retention, turnover, commitment to the organization and the profession. Little is known about determinants of job satisfaction and their relationship with overall job satisfaction among nurses in Calabar, Cross River State, Nigeria. The study was undertaken to assess the level of job satisfaction and the relationship between determinants and overall job satisfaction. Methods: A descriptive survey with a sample of 346 nurses selected through stratified random sampling was used in this study. A self-reported questionnaire labeled "Work Quality Index" was used in collecting data on job satisfaction. The instrument yielded a test-retest reliability of ${ }^{\circledR} 0.73$ to 0.85 . Data were computer analyzed using Statistical Package for Social Sciences (SPSS) version 15.0 for Windows. Results: Majority of respondents 262 (75.7\%) were between ages 31-40 years while most $(48.5 \%)$ had 16-25 years of working experience. The respondents were predominantly female $(88.4 \%)$. Regarding education, most of the respondents $(69.9 \%$ ) had diploma in Nursing while $28.6 \%$ were first degree holders. The mean overall of job satisfaction was 146.7. The results also revealed that majority of the respondents $265(82.4 \%)$ were moderately satisfied with their work. Nurses were least satisfied with their salaries. The level of achievement, advancement, responsibility, recognition, work itself, nursing practice environment, hospital policy, interpersonal relationship, salary, supervision and working conditions were significantly positively related to the overall job satisfaction. Conclusion: The study has shown that nurses in the hospital under study were not totally satisfied with their job. In view of the negative impact of lack of job satisfaction, the main recommendation was that all determinants of job satisfaction must be addressed by the government, hospital management and professional associations.
\end{abstract}

Keywords: Job Satisfaction, Nurses, Intrinsic or Motivating Factors, Extrinsicor Hygiene Factors

\section{Introduction}

The issue of global nursing shortage and the concepts of safe staffing have attracted prominent attention of World Health Organization [1], international and regional professional nursing organizations such as International Council of Nursing, West African College of Nursing and National Association of Nigerian Nurses and Midwives for decades [2]. Nursing shortage is a health system problem which results in adverse effect on the health and well-being of populations and the challenges to policy makers and planners in high and low income countries have never been experienced in this way.

According to [3], a turnover rate of $35 \%$ to $55 \%$ in the first year of employment has been reported in the US. As reported in [4], in the UK nursing employment fell to $82 \%$, 3 years after qualification in a longitudinal study of early career nurses. The cost of a US graduate nurse who leaves nursing within 1 year of qualification has been put at $\$ 40,000$ [5].[2] also reported that in sub-Saharan Africa (which includes Nigeria) nursing has a short fall of more than 60,000 nurses in relation to the estimated numbers needed to scale up priority intervention as recommended by the Commission on Macro-Economic Health.

Some of the critical issues during nursing shortages are: the demand for health services and nurses, continued 
growth of aging population, increasing population growth rates, and a growing burden of disease [2,6]. [7] noted that changing technology and economic crises have influenced the health care profession which includes nursing. Concurrently, the supply of available nurses dwindles as a result of aging nursing workforce, inadequate funding to recruit new nurses into the profession and growth of alternative career opportunities for women. Nurses also face multiple roles, heavy workloads, lack of administrative support, lack of in-service training and insufficient salary $[2,7]$.

Job satisfaction is defined as all the feelings which people have about their job which could be like (satisfaction) or dislike (dissatisfaction) of their job [8]. [4] view job satisfaction as important aspects of nurses' lives which could impact on patient safety, staff morale, productivity and performance, quality of care, retention and turnover, commitment to the organization and the profession. Relatedly, studies have shown a direct correlation between staff satisfaction and patient satisfaction in health care settings [9].

Exploring the future impact of nursing shortage, [10] reported that all sampled nurses felt that shortage will increase stress on nurses, lower patient care quality and cause nurses to abscond from the profession. [11] affirmed that high nurses turnover and vacancy rates affects access to health care. Continuously hiring employees is costly and frequent staff turnover affect employee's morale and impairs patient care [2]. Rapid turnover has been found to have negative physical and emotional impact on patients, resulting in a greater incidence of falls, medication errors, fears, anxiety, and feeling of hopelessness [11,12].

[13] found out that overall job satisfaction was the most important reason which caused nurses to choose to stay in a particular job. Relatedly, [14, 7] study on level of job satisfaction among nurses showed that they were moderately satisfied with their work. It could therefore be deduced from the above that job satisfaction is a complex phenomenon affected by the multiple variables. The factors leading to an employee satisfaction in an organization may be either intrinsic or extrinsic. Furthermore, intrinsic factors include rewards that a worker derives directly from performing the work itself while extrinsic rewards are those rewards from the boss or company. Sources of job satisfaction among nurses and its related factors from literature include: recognition [23,14]; salary and benefits $[14,15,16]$; working conditions $[14,17]$ relationship with patient/co-workers/supervisors $[14,18]$; work itself $[17,19,20]$; job advancement opportunities [9,21,22]; responsibility [23]; supervision [24]; organizational policy and administration [20,21,25,26]; supervision [24]; it has been noted that leadership style sometimes influence the subordinate level of job satisfaction [10] and the opinion of immediate supervisors had strong influence on the employee than overall company policies and procedures[27,28,29]

Evidence from literature suggests that nurses in early career in UK were least satisfied with pay and most satisfied with relationship [4,14]. Another study by [30] showed that nurses' job satisfaction was adversely affected by staff shortages, workload, frustration with management, pay, lack of development opportunities and equipment.

It was noted that the retention and recruitment of nurses have shown that low wages and poor job satisfaction are primary reasons why nurses leave their positions [16]. The dissatisfaction is often attributed to heavy workloads leadership styles, motivation, inadequate training and lack of respect [16]. It was concluded in a study that no single factor gives satisfaction to an employee in any organization [31]. Although, [32] posits that recruitment and retention efforts should concentrate on increasing financial incentives to staff members and create a desirable work place which would eventually lead to greater job satisfaction; because by embarking on such a policy the expertise required of direct caregivers, coupled with the heavy work load which often far exceeds the financial compensation they receive would be minimized.

In Calabar, public hospitals experience shortage of nurses as a result of flight of nurses to developed countries. This is however, not a unique situation in this place since other parts of Nigeria and other African countries experience same. Observation reveals the existence of one nurse to 2030 patients in a shift in some of the hospitals. Interaction also reveals complaints about heavy workload and challenging working environment. Exit interview of nurses who leave public hospitals revealed dissatisfaction with the job. Additionally studies on job satisfaction among nurses, in public hospitals in Calabar is scarce in literature, hence the importance of undertaking this study. Understanding of job satisfaction among nurses and its determinants will help managements of public hospitals to set and develop appropriate strategies and programmes that would not only lead to better job satisfaction among nursing work force, but would also increase productivity, efficiency and quality of care, and hopefully will increase patient satisfaction with care in public hospitals.

\section{Theoretical Framework}

The study was based on Hertzberg's Dual Factors Motivation theory: this theory postulates that the phenomenon of job satisfaction and /or no satisfaction is the function of two needs systems: intrinsic or motivators (achievements, recognition, work itself, advancement, responsibility and growth) and extrinsic or hygiene factors (supervision, company policy and administration, working conditions and interpersonal relations). The intrinsic and extrinsic factors enhance individual satisfaction of personal needs and experience of job satisfaction in a work environment. Motivation factors are the direct stimulating factors that give a person satisfaction in his work and kindle positive attitude to like and love his job. The intrinsic factors relate to work content; while the hygiene factors are related to the work environment. These factors are 
presumed to cause satisfaction or no satisfaction when not addressed by employers of labour $[33,34,35]$. The term "no satisfaction" is used in Herzberg's theory and not dissatisfaction because lack of satisfaction is implied "not a state of being dissatisfied".

The main objective of the study was to determine job satisfaction among nurses in public hospitals in Calabar, Cross River State. The specific objectives were:

1. To determine the level of job satisfaction among nurses

2. To determine the relationship between motivation factors (achievements, recognition, work itself, responsibility, and advancement); hygiene factors (policy and administration, supervision, salary, relationship and working conditions) and overall job satisfaction.

\section{Hypotheses}

(1) There is no significant relationship between level of advancement and overall job satisfaction among nurses

(2) There is no significant relationship between nurses' level of achievement and overall job satisfaction.

(3) There is no significant relationship between nurses' level of recognition and overall job satisfaction.

(4) There is no significant relationship between level of work and nurses' overall job satisfaction.

(5) There is no significant relationship between level of hospital policies and administration and overall job satisfaction of nurses.

(6) There is no significant relationship between level of nurses' salary, benefits and overall job satisfaction.

(7) There is no significant relationship between level of nurses working conditions and overall job satisfaction.

(8) There no significant relationship between nurses level of interpersonal relationship and overall job satisfaction.

\section{Methodology}

\subsection{Study Design}

The study was a cross sectional descriptive survey.

\subsection{Research Setting}

The study took place in two out of the three public hospitals in Calabar, Cross River State. These hospitals were chosen because they have relatively a higher number of nurses. Calabar is located in the rain forest belt in the SouthSouth Geopolitical Zoneof Nigeria. The city houses two local Government Areas (LGAs): Calabar South and Calabar Municipality. Calabar is the capital of Cross River State and is fast developing into a tourist center. It has two universities, an airport, seaport, many public and private enterprises.

\subsection{Study Population}

The study population consisted of all Registered Nurses working in public hospitals in Calabar. Public hospitals are owned by Federal and State Governments.

\subsection{Sample}

Samples of 346 nurses were selected from an accessible population of 550 nurses working in two public hospitals.

\subsection{Sampling Technique}

A stratified random sampling technique was used in order to include all strata of nurses.

\subsection{Data Collection}

The instrument for data collection was a questionnaire which had two sections: Section A covered characteristics of the respondents while section B was based on Work Quality Index developed by Whitley and Putzier [36]. It is a 7-point Likert scale reduced to 6 points for the purpose of this study. It consists of 38 items which is used for measuring nurses' job satisfaction in hospitals. The WQI has 6 sub scales which covers all aspects of the nurses' job. The subscales are: professional work environment, autonomy of practice, work worth to self and others, professional relationships, role enactment and benefits. These areas are also covered by Herzberg motivation and hygiene factors. The test-retest reliability coefficient was $\mathrm{r} 0.73$ to 0.85 which was considered adequate for the instrument to be used.

Face to face administration of the questionnaire was done by the researchers and assistants who were trained to collect the data. Completed copies questionnaires were collected on the same day. Data collection lasted for one week. Out of three hundred and fifty copies of questionnaire administered, only 346 copies were found complete and fit for analysis giving a response rate of $98.7 \%$.

\subsection{Ethical Consideration}

Ethical Committees of the two hospitals, which were used for the study, granted permission for the study to done in their establishments. Verbal consent was also obtained from the nurses who participated in the study. The purpose of the study was explained to all participants. Anonymity was maintained by not requesting for participants names on the questionnaire. The participants willingly completed and returned copies of questionnaire without any form of coercion.

\subsection{Data Analysis}

Descriptive statistics was used for analyzing sociodemographic characteristics. Correlational statistics was used in determining relationship between motivational factors, hygiene factors and overall job satisfaction. Computer analysis was done with Statistical Package for Social Sciences (SPSS) version 15.0 for Windows. 


\section{Results}

Table 1. Socio-demographic characteristics of Respondents on Job Satisfaction among nurses in Public Hospitals in Calabar $N=346$.

\begin{tabular}{lll}
\hline Characteristics & Frequency & Percentage \\
\hline Sex & & \\
Male & 36 & 10.4 \\
Female & 306 & 88.4 \\
Age & & \\
$21-30$ & 80 & 23.1 \\
31-40 & 262 & 76.7 \\
41-50 & 4 & 1.2 \\
Professional rank & & \\
Nursing Officer II & 55 & 15.9 \\
Nursing Officer I & 36 & 10.4 \\
Senior Nursing Officer & 36 & 10.4 \\
Principle Nursing Officer & 27 & 7,8 \\
Acting Chief Nursing Officer & 55 & 15.9 \\
Chief Nursing Officer & 137 & 39.6 \\
Years of working experience & & \\
$<5$ years & 71 & 20.5 \\
5-10 & 42 & 12.1 \\
11-15 & 13 & 3.8 \\
16-20 & 87 & 25.1 \\
21-25 & 81 & 23.4 \\
26-35 & 22 & 8.7 \\
Educational Qualification & & 69.9 \\
RN/Diploma & 242 & 28.6 \\
BSc & 99 & 1.5 \\
Master's degree & 5 & \\
\hline
\end{tabular}

Most of the respondents in this study were females 306
(88.4\%). Majority of the respondents were aged $31-40$ years $262(75.7 \%)$. Regarding education, most of the respondents $242(69.9 \%)$ had diploma in Nursing while 99 $(28.6 \%)$ were first degree holders, majority of the respondents' years of working experience ranged between $16-25$ years $168(48.5 \%)$. The overall satisfaction mean score was 146.7 with a standard deviation of 21.6. The level of satisfaction showed that majority of the respondents was moderately satisfied with their work $285(82.4 \%)$. The results also showed a positive correlation between motivation factors (achievement, recognition, work itself, responsibility advancement), hygiene factors (policy and administration, supervision, salary relationship and total job satisfaction)

Table 2. Levels of job satisfaction among nurses in public hospitals in Calabar, Nigeria.

\begin{tabular}{lll}
\hline Variable & No of respondents & percentage \\
\hline Dissatisfied & 20 & 5.80 \\
Moderately satisfied & 285 & 82.40 \\
Very satisfied & 41 & 11.80 \\
Total & 346 & 100 \\
\hline
\end{tabular}

Table 3. Relationship between determinants of job satisfaction and overall job satisfaction among nurses in public hospitals in Calabar, Nigeria.

\begin{tabular}{|c|c|c|c|c|c|c|c|c|c|}
\hline $\mathbf{s} / \mathbf{n}$ & Variable & $\mathbf{X}$ & SD & $\mathbf{N}$ & r-cal & r-crit & p & df & Remarks \\
\hline \multirow{15}{*}{1} & Advancement & 17.11 & 3.48 & 346 & & & & & \\
\hline & Job satisfaction & 146.69 & 21.57 & & .58 & .148 & 0.01 & 344 & *Significant \\
\hline & Responsibility & 11.22 & 2.96 & 346 & & & & & \\
\hline & Job satisfaction & 146.69 & 21.57 & & .61 & .148 & 0.01 & 344 & *Significant \\
\hline & Recognition & 12.28 & 3.16 & 346 & & & & & \\
\hline & Job satisfaction & 146.69 & 21.57 & & .65 & .148 & 0.01 & 344 & *Significant \\
\hline & Work itself & 24.23 & 4.49 & 346 & & & & & \\
\hline & $\begin{array}{l}\text { Hospital policy and } \\
\text { administration }\end{array}$ & 10.67 & 3.29 & 346 & & & & & \\
\hline & Job satisfaction & 146.69 & 21.57 & & .66 & .148 & 0.01 & 344 & *Significant \\
\hline & Interpersonal relationship & 13.02 & 2.98 & 346 & & & & & \\
\hline & Job satisfaction & 146.69 & 21.57 & & .69 & .148 & 0.01 & 344 & *Significant \\
\hline & Salary & 7.05 & 3.75 & 346 & & & & & \\
\hline & Job satisfaction & 146.69 & 21.57 & & .31 & .148 & 0.01 & 344 & *Significant \\
\hline & Work conditions & 18.34 & 4.29 & 346 & & & & & \\
\hline & Job satisfaction & 146.69 & 21.59 & & .71 & .148 & 0.01 & 344 & *Significant \\
\hline
\end{tabular}

\section{Discussion of Findings}

The findings indicated that nurses were moderately satisfied with their jobs. This result is consistent with previous findings on the level of job satisfaction [14,31]. It should be noted that no single factor be it intrinsic or extrinsic gives overall job satisfaction but all the factors must be considered in order to get the best out of the nurses. The results also revealed that all factors (motivation and hygiene factors) had positive significant correlation with overall job satisfaction. This result is consistent with the findings of [11]. Motivation factors such as achievement, recognition, work itself, responsibility and advancement are important for job satisfaction. Achievement is linked with nurses having opportunities to make independent nursing decisions as professionals, with regular feedback on their performances. Nurses need to feel challenged when there is no improved patient outcome although; this may result in frustration, depression and lack of job satisfaction. Work that give nurses 
opportunity to use a wide range of professional skill and ability will enhance job satisfaction among nurses.

Recognition is associated with job satisfaction as confirmed by $[14,33]$ motivational factors. Acknowledgement of achievement by the ward manager or immediate supervisor is motivational because it helps to promote self-esteem. [18] discovered that nurses experience frustration and tension in the workplace as a result of lack of support and recognition by their supervisor. Advancement scored fourth highest mean and was a positive significant factor associated with job satisfaction in this study. This result is in consonance with [14] where it was reported that there was a statistically significant association between professional training, the number of professional training attended in the recent two years and job satisfaction. In a related study, [21,22] also noted that professional growth opportunities, workload, dissatisfaction with work hazards, and relationship with co-workers predicted nurses turnover. Responsibility and interpersonal relationship scored low in this study although positive statistical significant relationship was established. This result may be related to the fact that in tertiary health institutions in Nigeria nurses are not allowed to carry out certain procedures whereas in the primary health centres they may be allowed as they may be the only health worker on shift duty. Nevertheless, it was reported that in Italy, one of the factors influencing job dissatisfaction was relationship with other health workers such as medical doctors, relationship with patients and their families [14].

Work itself is also related to job satisfaction as supported by $[17,19]$. Work itself in this study had the highest mean score and a statistically significant positive relationship with job satisfaction. This result may be related to the continuing education of nurses in the hospitals under study, therefore enhancing the nurses' role in helping relationship and increase patient's satisfaction as regards their care. Nurses that are satisfied with the role they play as nurses will be more satisfied than those who are dissatisfied with their roles. The nurse who assumes a helping role to the patient is likely to see the profession as more rewarding. Negative or positive attitude of the nurse towards nursing influence job satisfaction or dissatisfaction, therefore, attitude of the nurse towards her job should not be overlooked. Furthermore, intrinsic work values such as "the work itself" and patient care issues were identified in a study as factors that are related to job satisfaction [20].

Hygiene factors such as hospital policy and administration is associated with job satisfaction as confirmed by studies by $[21,22,25,26]$. However, a study on association between hospital policy, administration and job satisfaction by [26] which took place in private hospitals in England revealed that nurses were satisfied with organization and administrative policies, supervision and interpersonal relationship contrary to [25] revelation that critical care nurses in Northern Italy had low job satisfaction and higher intension to leave which was associated with hospital policy and work in private hospitals. However, in Canada, many public health nurses noted that their job dissatisfaction correlated with organizational policy [11].

Another hygiene factor which is associated with job satisfaction is salary. Salary in this study had the least mean score which was corroborated by $[14,25]$. The result in this study is in contrast to what happens in Canada and United Stated (developed countries) where nurses feel more satisfied with their wages [16]. Indeed [16] also noted that low wages and poor job satisfaction were the foremost reasons for nurses leaving their jobs. In Nigeria which is a developing country, although, nurses enjoy better pay than teachers but are not comparable to other health care workers. However, salary increase which is occasionally enjoyed by workers in Nigeria, without effective fiscal control robs people including nurses of their purchasing power resulting in dissatisfaction with pay. Another factor with a high mean score was the work conditions and this was significantly associated with job satisfaction. This result is supported by [14] which revealed a significant relationship between working conditions and nurse's job satisfaction in Aceh Timur District in Indonesia.

According to [30], nurses' job satisfaction was negatively influenced by staff shortages, workload, frustration with management, pay, lack of development opportunities and equipment. The result in the current study may be related to the commitment of the management of the hospital to ensure a conducive working environment for health workers through employment of new nurses, provision of working materials, training opportunities, and management support among others. [18] observed that deterioration in working conditions may be stressful resulting in anger and depression

The determinants of job satisfaction as identified by $[32,33,35]$ are very important in view of negative impact of dissatisfaction on patient and staff (high incidence of falls, medication errors, fears and anxiety and feeling of hopeless. On the other hand job satisfaction is also linked with effectiveness of the health system.

\section{Conclusion}

Nurses were not fully satisfied with their work. Secondly, motivation factors (achievement, recognition, work itself, responsibility advancement) and hygiene factors (policy and administration, supervision, salary relationship) had positive significant correlation with overall job satisfaction among nurses. These results have implications for nurses' employers/managers/administrators to consider all the factors in order to retain nurses in their workplaces and increase health system effectiveness since nurses make up the largest health care providers. These actions related to addressing motivation and hygiene factors to increase nurses' job satisfaction when implemented will also result in improved mental and social health of the nurses.

\section{Recommendations}

Therefore the following recommendations were proffered: Hospital Management, government and National Association 
of Nigerian Nurses and Midwives should address all determinants of job satisfaction through effective policies implementation, salaries and benefits, conducive environment for work, reward for achievements among others. The limitation of this study is that it took place in only two hospitals in the state. It is suggested that an elaborate study should be done in the whole state to know the level of job satisfaction in the state.

\section{References}

[1] Olade RA. Reforms in nursing education and practice in the 21 st century which way forward? West African Journal of Nursing 2005;16: 4 - 10 .

[2] Adeleye SA. Nursing personnel shortage and its effect on health care delivery, West Africn Journal of Nursing 2006;17: 174-177

[3] Williams CA, Goode CJ, Krsek C. Post baccalaureate Nurse residency 1- year outcome, Journal of Nursing Administration 2007; 37: 357-365.

[4] Robinson S, Murrells T, Clinton M. Highly qualified and highly ambitious: implication for workforce retention of realizing the career expectations of graduate nurses in England. Human Resource Management Journal 2006; 16: 287-312.

[5] Helfer D, Graf E. Graduate nurse perception of the work experience. Nursing Economics 2006; 24: 428-435.

[6] Kassner E, Bertel RW. Midlife and older Americans with disabilities: who gets help? A chant book; Public Policy Institute, AARP; 1998

[7] Sermsri S. Socio Cultural perspective in health. (2nded.) NakhonPathom: AIHD - Mahidol Univ. Thailand; 2007.

[8] Spector PE. Job satisfaction. Sage, Thousands Oaks, CA; 1997.

[9] Al-AameriAS. Job satisfaction and organizational commitment for nurses Saudi Medical Journal 2000; 21: 231235 .

[10] Al-HussamiM. A study of Nurses' Job satisfaction: The relationship to organizational commitment Perceived organizational support. Transactional leadership Transformational leadership and level of education. European Journal of Scientific Research 2008; 22: 286-295

[11] Best M. Thurston N. (2004) Measuring nurse job satisfaction. Journal of Nursing Administration 34; (6) 283-290.

[12] Sofie J, Belza B, Young H. Health and Safety risk at a skilled nursing facility: Nursing assistants' perceptions. Journal of Gerontology Nursing 2003; 29:13-21.

[13] Urden LD. What makes nurses stay? Nursing Management $1999 ; 30: 27-30$.

[14] Saifuddin AR, HongKrailert N, Sermsri S. Journal of Public Health and Development 2008; 6:153-161.

[15] Price M. Job satisfaction of registered nurses working in an acute hospital. British Journal of Nursing 2002; 11(4), 275280
[16] Lu H, While AE, Barriball, KL. A model of Job satisfaction of nurse: a reflection of nurses working lives in Mainland China. J. of Adv. Nurs 2007; 58, 468-79.

[17] McShane SL, Glinow, VA. Organizational behavior: Emerging knowledge and practice for the real world. McGraw-Hill/Irwin New York 2010

[18] Aiken LH, Clarke SP, Sloan DM, Sochalski JA, Busse R, Clarke H. et al. Nurses' report on hospital care in five countries. Health Affairs 2001; 20(3), 43-53

[19] Adams A, Bond S. Hospital nurses' job satisfaction, individual and organizational characteristics. Journal of Advance Nursing 2000; 32(3), 536-543

[20] Kettle JL. Factors affecting job satisfaction in the Registered Nurse. 2001. Retrieved http:www.juns.nursing.arizona.edu/articles/Fall\%202002/Kettl e.htm Accessed 2nd June, 2015

[21] Tzeng HM. The influence of nurses' working motivation and job satisfaction on intention to quit: an empirical investigation in Taiwan. International Journal of Nursing Studies 2002a, 39, 287-878.

[22] TzengHM. Satisfying nurses on job factors they care about: a Taiwanese perspective. Journal of Nursing Administration 2002b; 32(6), 306-309.

[23] Price M. Job satisfaction of registered nurses working in an acute hospital. British Journal of Nursing 2002, 11(4), 275-280

[24] Masroor MA, Fakir J. Level of job satisfaction and intent to leave among Malaysian nurses. Semiannual Publication 2010; 3(1), 123.

[25] Cortse CG. Predictors of critical care nurses' intention to leave the unit, the hospital, and the nursing profession. Open Journal of Nursing 2012, 2, 311-326. http://dx.doi.org./10.4236/ojn.2012.223046

[26] Lephalala RP, Ehlers VJ, Oosthuizen MJ. Factors influencing nurses' job satisfaction in selected private hospitals in England. Curationis 2008; 31(3), 60-69.

[27] Fletcher CE. Hospital RNs' job satisfaction and dissatisfactions. Journal of Nursing Administration 2001; $31(6), 324-331$

[28] Kleinman CS. Leadership roles, competencies and education: how prepared are our nurse managers. Journal of Nursing Administration 2003; 33(9), 451-455

[29] Wynd CA. Current factors contributing to professionalism in nursing. Journal of Professional Nursing 2003; 19(5), 251-261

[30] Hennessy ES, Minnaar A. Job Satisfaction of nursing in a public hospital with a high number of HIV and AIDS patients. A paper presented at International Council of Nursing 24th Quadrennial Congress, 2009.

[31] Lashonda-Bare L. (2004). Factors that most influence job satisfaction among cardiac nurses in an acute care setting. http://www.nursing society org/youbelonghere/YBH.VI-VI-5 bhtml. Retrieved June 20, 2006

[32] Wilson AA. Impact of management development on nurse retention 2005. In: Al-Hussami M. A study of Nurses' Job satisfaction: The relationship to organizational commitment Perceived organizational support. Transactional leadership Transformational leadership and level of education. European Journal of Scientific Research 2008; 22: 286-295 
[33] Herzberg F. The motivation to work (2nd ed.) New York: John Whiley and Sons 1959.

[34] Shortell SM, Kaluzny AD. Health care management: Organisational design and behaviour (5thed.) USA: Thompson-Delmar Learning; 2006.
[35] Vroom VH. Work and motivation. New York: John Wiley and Sons; 1994.

[36] Whitley MP, Putzier DJ. Measuring nurses satisfaction with the quality of their work and work environment. Journal of Nursing care quality 1994; 8 (3), 42-51. 